\title{
Imageless Navigation Versus Conventional Open Wedge High Tibial Osteotomy: A Meta-Analysis of Comparative Studies
}

\author{
Hyun Jung Kim, $\mathrm{PhD}^{1, \star}$, Jung-Ro Yoon, $\mathrm{MD}^{2, \star}$, Gi Won Choi, $\mathrm{MD}^{2}$, and Jae-Hyuk Yang, $\mathrm{MD}^{2}$ \\ ${ }^{1}$ Department of Preventive Medicine, Korea University College of Medicine, Seoul; ${ }^{2}$ Department of Orthopaedic Surgery, Veterans Health Service Medical Center, Seoul, \\ Korea
}

\begin{abstract}
Purpose: To summarize and compare radiological and clinical outcomes of open wedge high tibial osteotomy (HTO) using imageless computerassisted navigation with conventional HTO.

Methods: A literature search of online register databases was conducted. The risk ratio (RR) of radiological outliers and mean differences in clinical outcomes were compared between navigated and conventional HTOs. Radiological results were evaluated by subgroup analyses according to the study period (concurrent/consecutive) and the use of locking fixation device.

Results: Seven comparative studies with a total sample size of 406 knees were included in this review. Radiographically, the mechanical axis [MA] was within the acceptable range $\left(0^{\circ}-6^{\circ}\right)$ in $83.7 \%$ of the navigation HTO group, showing significant difference from $62.1 \%$ of the conventional HTO group. Clinically, despite the forest plot demonstrating a general trend of favoring the navigation system, there were not sufficient studies to determine statistical significance in the meta-analysis. None of the subgroup analyses demonstrated significant differences in the RR of MA outliers.

Conclusions: The present meta-analysis indicates that the use of navigation in open wedge HTO improves the precision of mechanical alignment by decreasing the incidence of outliers; however, the clinical benefit is not conclusive. Additionally, none of the subgroup analyses demonstrated significant difference in the RR of MA outliers.
\end{abstract}

Keywords: Tibia, Osteotomy, Computer-assisted, Navigation, Meta-analysis

\section{Introduction}

Valgization high tibial osteotomy (HTO) was first described in the $1960 \mathrm{~s}^{1)}$. It has been considered a successful procedure to correct varus malalignment by shifting the weight-bearing axis to the unaffected lateral knee compartment. Brouwer et al. ${ }^{2)}$, in their Cochrane review, analyzed 13 high quality studies to demonstrate

Received April 22, 2015; Revised June 25, 2015;

Accepted June 28, 2015

Correspondence to: Jae-Hyuk Yang, MD

Department of Orthopaedic Surgery, Veterans Health Service Medical Center, 53 Jinhwangdo-ro 61-gil, Gangdong-gu, Seoul 05368, Korea

Tel: +82-2-2225-1609, Fax: +82-2-2225-1910

E-mail: jaekorea@gmail.com

*The first two authors contributed equally to this study.

This is an Open Access article distributed under the terms of the Creative Commons Attribution Non-Commercial License (http://creativecommons.org/licenses/by-nc/4.0/) which permits unrestricted non-commercial use, distribution, and reproduction in any medium, provided the original work is properly cited. the efficacy of HTO. All the studies included patients with medial compartment arthritis. They suggested that knee osteotomy was an effective treatment for improving knee function and providing pain relief. In general, HTO has been considered a better choice for younger and physically active patients who suffer from unicompartmental knee osteoarthritis.

After the introduction of computer-assisted systems for orthopedic surgery of the spine $e^{3)}$ and pelvis ${ }^{4)}$ and total joint replacement ${ }^{5)}$, they have also been used for $\mathrm{HTOs}^{6}$. Computer navigation systems were designed to improve the precision of implant positioning, and the technology has continued to evolve with hardware and software upgrades. Based on a review of current literature suggesting the use of computer-assisted navigation system for improvement in limb alignment and implant positioning $^{7-10)}$, we conducted a meta-analysis of comparative studies to determine whether computer-assisted navigation HTO improves limb alignment compared to conventional HTO. The hypothesis was that navigation HTO would result in more accurate limb 
alignment with lesser amount of outliers and better clinical outcomes than conventional HTO.

\section{Methods}

\section{Research Question}

Does computer-assisted navigation HTO improve radiological alignment compared to conventional HTO?

\section{Data Source and Search Strategy}

Clinical trials that compared computer-assisted navigation HTO with conventional HTO were identified. An electronic literature search was performed using MEDLINE, EMBASE, Cochrane library database, and KoreaMed. Keywords were selected based on the Cochrane acronym; population, intervention, comparison, and outcomes format of the research question. The following keywords were used along with the Boolean search function: computer-assisted, navigation, image-guided, osteoarthritis, genu varum, genu valgum, osteotomy, tibial, and knee. Different search protocols were employed for each database (Table 1). The last electronic search was carried out on September 30, 2014. The entire search process was conducted in four phases as per guidelines from PRISMA (Preferred Reporting Items for Systematic Reviews and Meta-analyses) statement (http://www. prisma-statement.org).

\section{Inclusion and Exclusion Criteria}

All types of studies (randomized controlled trials, non-randomized cohort studies, and retrospective studies) were included. Two authors (Yang and Choi) identified the titles and abstracts and any disagreements were resolved by consensus. The abstracts, regardless of language and years of publication, were screened based on the following inclusion criteria: 1) patients undergoing HTO had operations using either a computer-assisted or a conventional technique; 2 ) the study was a comparative study (either randomized controlled trials and/or retrospective studies); 3) there was a report on at least one of the radiographic or clinical outcome measures described subsequently. Only studies on computer-assisted navigation HTO vs. conventional HTO were selected for analysis. Some articles were excluded from this review because they were non-comparative studies or non-human studies, or had inadequate study designs. In addition, since there was only one article on closed HTO $^{11}$, it was also excluded.

\section{Data Collection}

Data from included studies were extracted independently by two of the authors (Yang and Choi). Since restoration of the limb alignment to slight valgus position (mechanical axis [MA] of $0^{\circ}-$ $6^{\circ}$ ) is the major goal of HTO, this radiological measure was used as a primary endpoint. Radiological outcome data were comprised of mechanical/anatomical leg axis, coronal tibial angle, and sagittal tibial angle. Functional scores were used as the secondary endpoint, which included the Hospital for Special Surgery (HSS) knee scoring system, Knee Society score (KSS) (summation of the functional and knee scores), Lysholm knee scoring scale, modified Cincinnati knee rating score, and visual analogue scale (VAS). In addition, study setting, study year, population, type of navigation system, method of osteotomy gap management (usage of bone graft material), and the type of fixation device were documented.

\section{Statistical Analysis and Synthesis of Results}

For continuous variables, a random effect model was used to measure the weighted mean differences. For dichotomous variables, such as the prevalence of outliers of the leg axis alignment, the differences were determined using the risk ratio (RR) and 95\% confidence interval (CI) as the summary statistics. Radiological outcome was considered "acceptable" when the MA was $0^{\circ}-6^{\circ}$, whereas "outlier" when the value was less than $0^{\circ}$ or more than $6^{\circ}$. $I^{2}$ statistic was used to evaluate statistical homogeneity. A score between $0 \%$ and $100 \%$ is possible on the $\mathrm{I}^{2}$ statistic. A score of $\leq 25 \%$ corresponds to low heterogeneity, $50 \%$ to moderate, and $75 \%$ to high heterogeneity ${ }^{12)}$. Forest plots were also used to assess heterogeneity. The chi-square statistic p-value was used to determine homogeneity. The lower the p-value is, the greater the tendency for a study to be heterogeneous. Generally, a p-value of $<0.05$ is considered to suggest heterogeneity. The RR was utilized to check probability relationship between two binary variables. A RR of 1 implies that the event occurs equally in both groups. A RR of $>1$ indicates that the event is more likely to occur in the first group (conventional HTO group in this review). Further subgroup analyses were performed with regard to the radiological outliers according to the consecutive vs. concurrent patient series and the use of a fixation device. All statistical analyses were performed using RevMan ver. 5.3 (The Nordic Cochrane Centre, Copenhagen, Denmark) and SPSS ver. 10.1 (SPSS Inc., Chicago, IL, USA).

\section{Results}

\section{Search Results}

A total of 397 articles were identified from the keywords search 
Table 1. Search Protocol

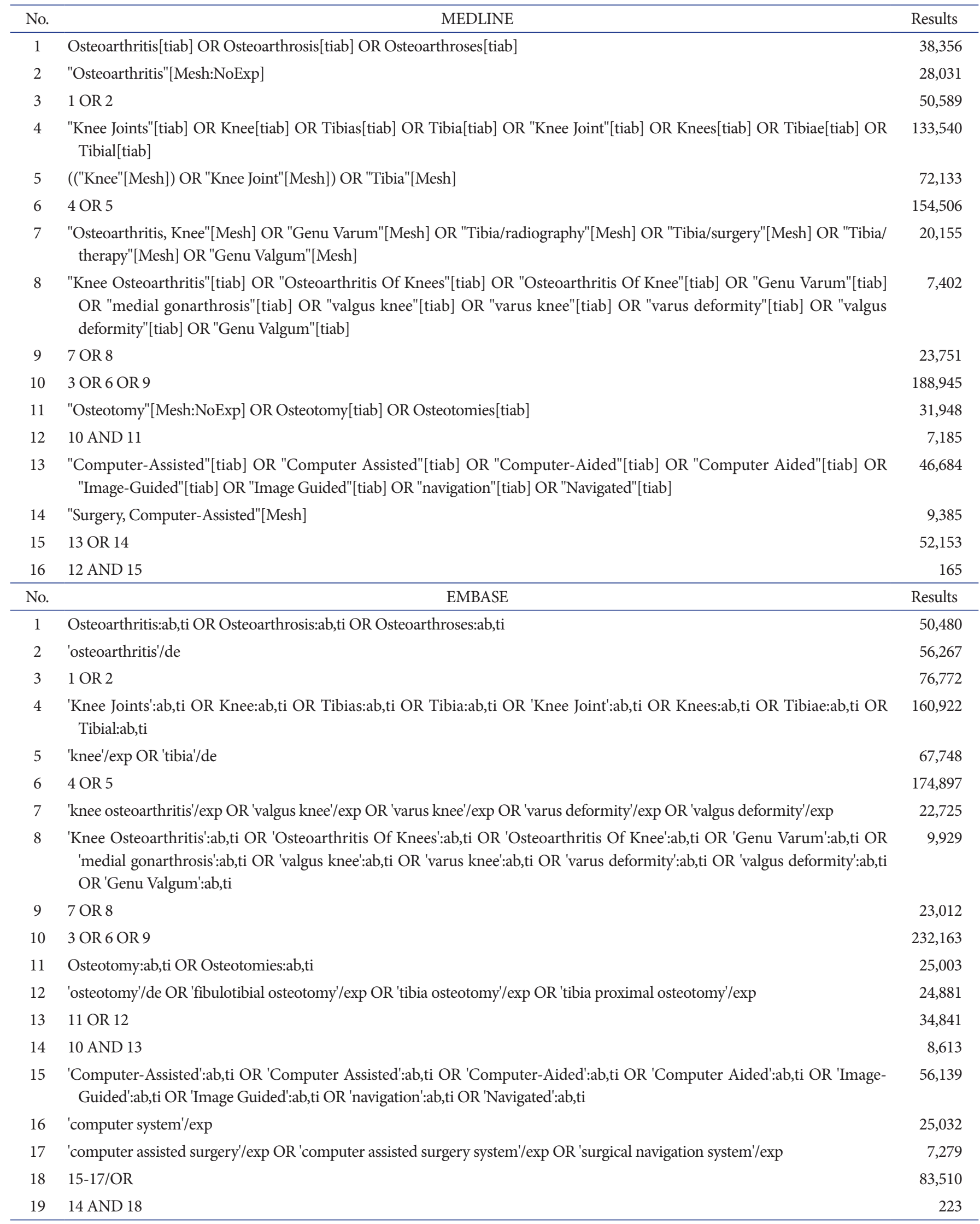


Table 1. Continued

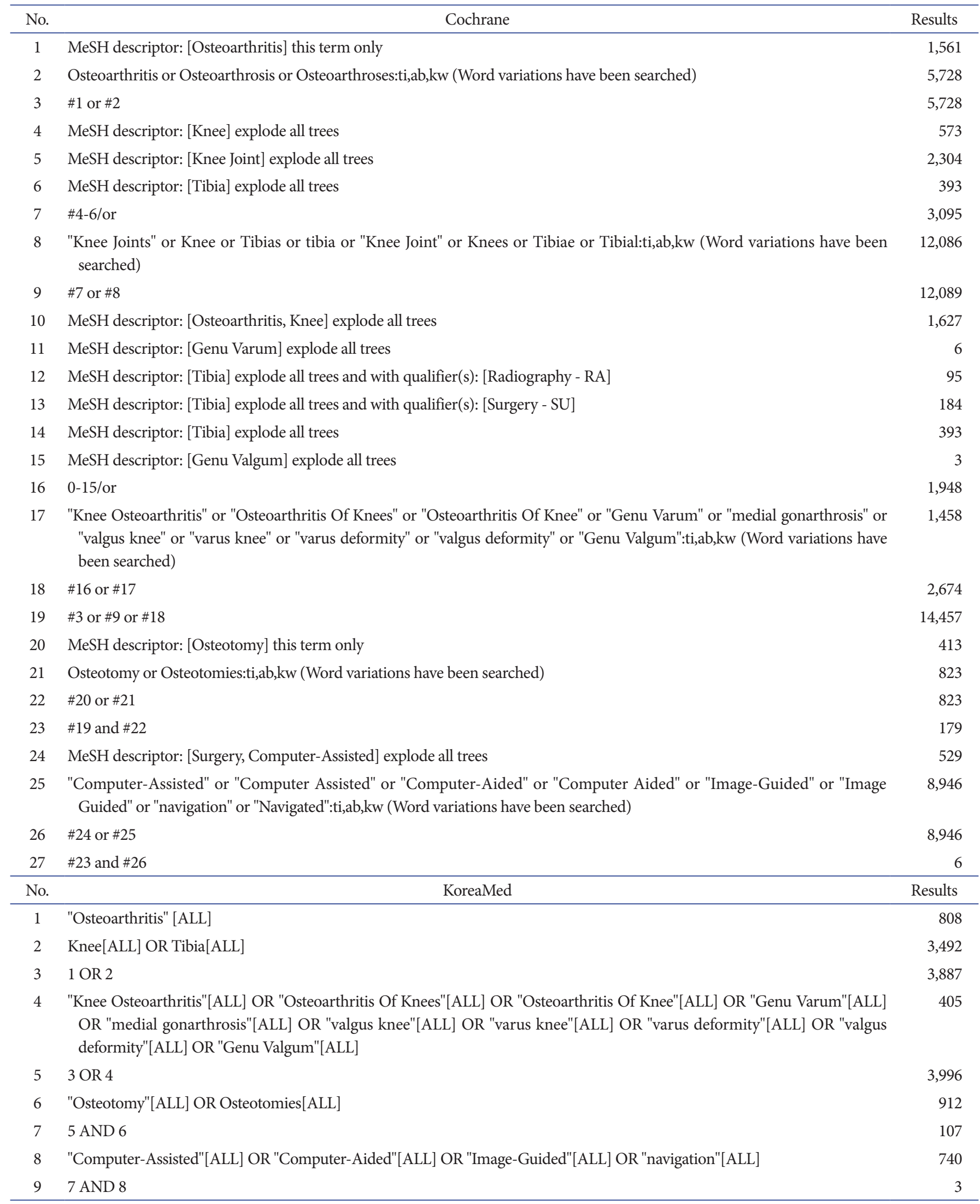


(MEDLINE: 165, EMBASE: 223, Cochrane: 6, and KoreaMed: 3), and 377 studies were excluded after reviewing titles and abstracts. The remaining 20 studies were evaluated for full review and 13 studies were excluded for various reasons, leaving 7 studies eligible for review (Fig. 1). All studies were written in English, and they were all retrospective comparative studies. All studies were on open $\mathrm{HTO}^{13-19)}$. All studies used the Orthopilot Aesculap navigation system (B. Braun-Aesculap, Tuttlingen, Germany). There were 3 studies $^{13,15,19)}$ with consecutive and 3 studies $^{16-18)}$ with concurrent patient series. Allograft bone material was used in 5 open HTO studies ${ }^{13-15,18,19)}$. Two studies ${ }^{16,17)}$ did not mention whether they used bone material for the osteotomy gap. Autogenous bone material was used for conventional HTO group in 1 study ${ }^{18)}$. Fixation was performed with a locking device in 3 studies ${ }^{13,16,17)}$ and a non-locking device in 4 studies $^{14,15,18,19)}$. The characteristics of included studies are presented in Table 2.

\section{Quality Assessment}

The methodological quality of each study was assessed using the Newcastle-Ottawa scale (NOS) ${ }^{20)}$. The assessment was carried out on three domains: study group selection, inter-group comparability, and ascertainment of exposure and outcome of interest. With regard to the "selection" (four numbered items) and "exposure" (three numbered items) domains, each assessed study could be awarded a maximum of one star for each numbered item. Regarding the "comparability" (one numbered item) domain, a maximum of two stars could be awarded. On the NOS, the higher the score, the higher the study quality (Table 3). All of the scores were determined by the two reviewers (Kim and Yoon), first independently and then by consensus. Details on the NOS- based methodological quality assessment of the included studies are presented in Table 3. The non-randomized studies had cohort and control groups (in each study) that were well-matched in terms of demographics, prognostic variables, and surgical technique.

\section{Clinical Results}

Three studies ${ }^{16,17,19)}$ did not report preoperative and postoperative clinical outcomes. There were 3 studies $^{13,15,18)}$ using Lysholm scoring system, 2 studies ${ }^{13,14)}$ using KSS, 1 study ${ }^{15)}$ using HSS score, 1 study ${ }^{14)}$ using VAS, and 1 study ${ }^{14)}$ using modified Cincinnati rating system questionnaire. Although the forest plot demonstrated a general trend of clinical outcomes (KSS and Lysholm scoring system) favoring navigation-assisted HTO (Fig. 2), there were not sufficient study results to determine statistical significance for the meta-analysis.

\section{Radiological Results}

The MA of the lower limb was the most frequent measurement ${ }^{14-16,18,19)}$, with an ideal value defined as $0^{\circ}-6^{\circ}$. Multiple studies measured the anatomical femoro-tibial angle (FTA), MA\%, and medial proximal tibial angle (MPTA). Several papers ${ }^{13-15,18)}$ included the posterior slope angle of the tibia or sagittal tibial alignment and the change in tibial slope angle, but due to various measurements, such studies were not included in the metaanalysis.

Five studies ${ }^{13,14,16,17,19)}$ presented the radiological results in terms of the number of knees in which the measured angle did not fall within the acceptable range; "outlier" with an MA of less than $0^{\circ}$ or more than $6^{\circ}$ (Table 4$)$. In these 5 studies $(279 \mathrm{knees})^{14,15,17,18,20)}$,
Initial search: total 397 studies identified (MEDLINE: 165, EMBASE: 223, Cochrane: 6, KoreaMed: 3)
377 articles discarded after review of titles and abstracts

Potentially relevant: 20 studies selected for full review

$\longrightarrow \quad \begin{aligned} & 13 \text { full-text articles excluded: } \\ & \text { - Duplication } \\ & \text { - Case series } \\ & \text { - Review articles } \\ & \text { - Non-human studies } \\ & \text { - Inadequate study design } \\ & \text { - Closed high tibial osteotomy study }\end{aligned}$

Meeting entry criteria: 7 articles
Fig. 1. PRISMA (Preferred Reporting Items for Systematic Reviews and Meta-analyses) flow diagram. 


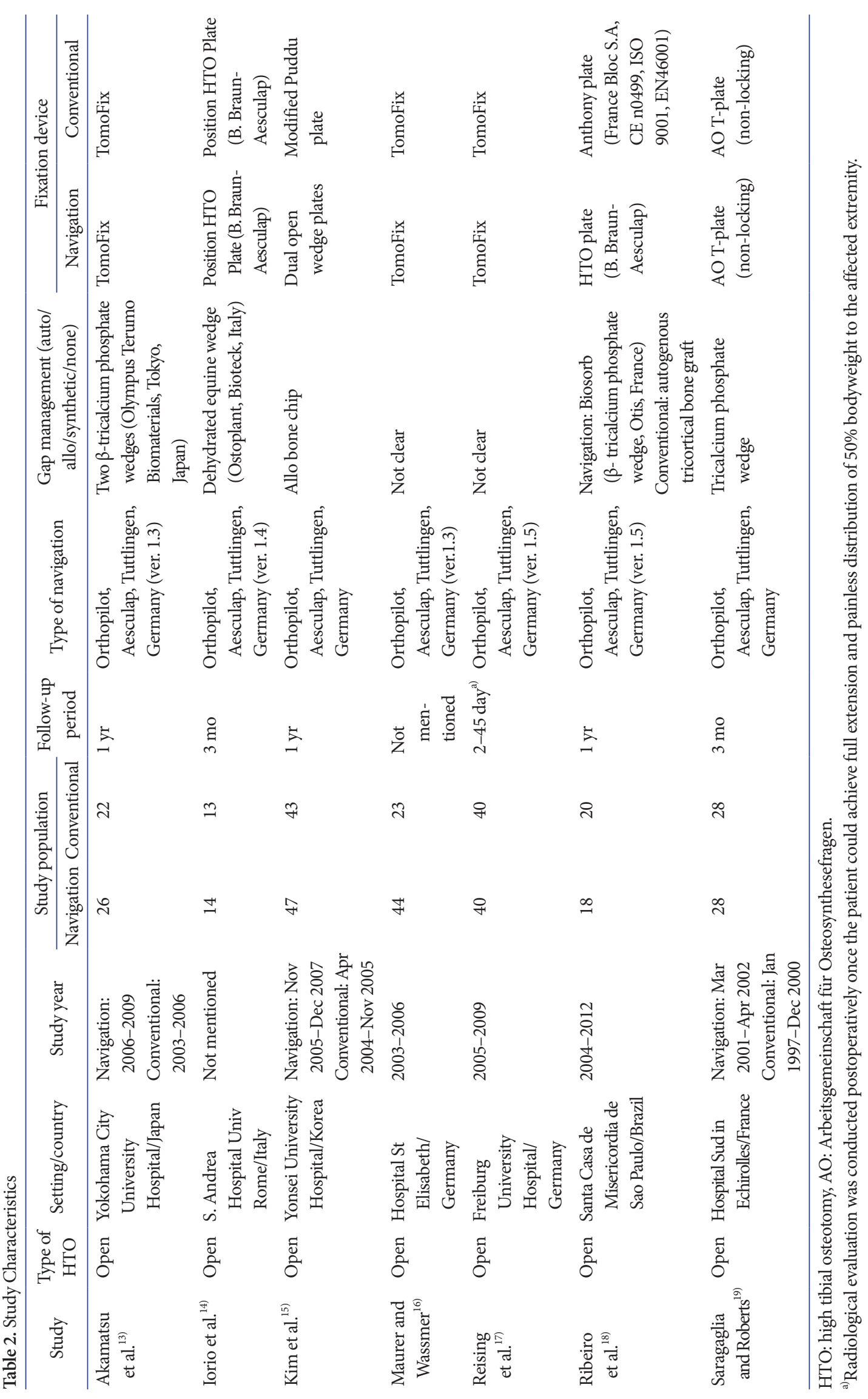


$83.7 \%$ (range, $65 \%$ to $100 \%$ ) of the computer-assisted navigation HTO group showed an acceptable range (MA of $0^{\circ}-6^{\circ}$ ), significantly different from the $62.1 \%$ (range, $23 \%$ to $78 \%$ ) of the conventional HTO group ( $\mathrm{RR}=1.37, \mathrm{p}<0.01,95 \%$ CI [1.06-1.78], $\mathrm{I}^{2}=63 \%$ ) (Fig. 3). Regarding the MA malalignment of less than $0^{\circ}$ or more than $6^{\circ}$ (outliers), computer-assisted navigation HTO significantly reduced the incidence of outliers compared to conventional HTO.

Further subgroup meta-analysis was performed to identify any variable factors affecting the relative RR of MA outliers. Regarding the comparison of consecutive vs. concurrent patient series, chi-square test showed a p-value of $>0.1$ (i.e., 0.84) and $\mathrm{I}^{2}$ statistic of $0 \%$, suggesting low heterogeneity (Fig. 4). On the comparison of fixation with a locking device vs. a non-locking device, chi square test showed a p-value of $>0.1$ (i.e., 0.40 ) and $\mathrm{I}^{2}$ statistic of $0 \%$, suggesting low heterogeneity (Fig. 5). None of the subgroup analyses demonstrated significant influence of the variable fac-

Table 3. Newcastle-Ottawa Quality Assessment Scale (Cohort Study) ${ }^{20)}$

\begin{tabular}{|c|c|c|c|}
\hline Author & $\begin{array}{l}\text { Selection } \\
(\star \star \star \star \star \star \star ~\end{array}$ & $\begin{array}{c}\text { Comparability } \\
(\star \star \star)\end{array}$ & $\begin{array}{l}\text { Exposure } \\
(\star \star \star \star)\end{array}$ \\
\hline Akamatsu et al. ${ }^{13)}$ & 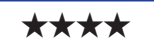 & $\star$ & $\star$ \\
\hline Iorio et al. ${ }^{14)}$ & 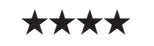 & $\star$ & $\star$ \\
\hline Kim et al. ${ }^{15)}$ & 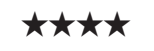 & $\star$ & $\star$ \\
\hline Maurer and Wassmer ${ }^{16)}$ & 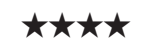 & $\star$ & \\
\hline Reising et al. ${ }^{17)}$ & 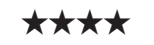 & $\star \star \star$ & \\
\hline Ribeiro et al. $^{18)}$ & 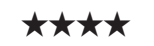 & 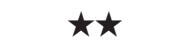 & $\grave{\lambda}$ \\
\hline Saragaglia and Roberts ${ }^{19)}$ & 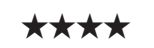 & $\star \star \star$ & \\
\hline
\end{tabular}

tors on the RR of MA outliers.

\section{Complications}

Clinical and radiological complications were reported in 3 studies $^{13-15)}$. Kim et al. ${ }^{15)}$ reported $2 / 47$ cases $(4.3 \%)$ of delayed union, $1 / 47$ case $(2.1 \%)$ of varus collapse in the computer-assisted navigation HTO group, and 2/43 cases of delayed union (4.7\%) in the conventional HTO group. Akamatsu et al. ${ }^{13)}$ reported lateral unstable knee (cortex breakage and tibial plateau fracture) in 2/26 cases $(19.2 \%)$ in the computer-assisted navigation HTO group, and $4 / 24$ cases $(16.7 \%)$ in the conventional HTO group. Iorio et al. $^{14)}$ reported no complication in the computer-assisted navigation HTO group and 2/13 cases (15.4\%) of broken screws in the conventional HTO group.

\section{Discussion}

The most important finding of the present study was that computer-assisted navigation HTO resulted in more accurate limb alignment (in terms of MA) with lesser outliers compared to conventional HTO. For optimum results in HTO, precise planning for limb alignment is needed, for which both computer-assisted and conventional techniques are currently used. Previously known conventional methods for correction angle calculation include the trigonometric principle, weight bearing line method, grid lines or reference to the joint line surface; however, their precision is limited and there is a high risk of technical error ${ }^{21)}$. With respect to the radiological alignment after open wedge $\mathrm{HTO}$, computer-assisted technique seems to be more useful in achiev-

Table 4. Postoperative Radiological Parameters and Outliers

\begin{tabular}{|c|c|c|c|c|c|c|c|}
\hline \multirow{3}{*}{ Study } & \multirow{3}{*}{$\begin{array}{l}\text { Radiological } \\
\text { parameters }\left(\left(^{\circ}\right)\right.\end{array}$} & \multicolumn{6}{|c|}{ Radiological outcome distribution } \\
\hline & & \multicolumn{3}{|c|}{ Navigation (\%) } & \multicolumn{3}{|c|}{ Conventional (\%) } \\
\hline & & Varus $\left(<0^{\circ}\right)$ & $\begin{array}{l}\text { Acceptable range } \\
\qquad\left(0^{\circ}-6^{\circ}\right)\end{array}$ & Valgus $\left(>6^{\circ}\right)$ & Varus $\left(<0^{\circ}\right)$ & $\begin{array}{l}\text { Acceptable range } \\
\qquad\left(0^{\circ}-6^{\circ}\right)\end{array}$ & Valgus $\left(>6^{\circ}\right)$ \\
\hline $\begin{array}{l}\text { Akamatsu } \\
\text { et al. }^{13)}\end{array}$ & $\begin{array}{l}\text { FTA, } \triangle \mathrm{MPTA} \\
\mathrm{PSA}, \Delta \mathrm{TS}\end{array}$ & $0 / 28(0)$ & $19 / 28(67.9)$ & $9 / 28(32.1)$ & $5 / 31(16.1)$ & $22 / 31(71)$ & $4 / 31(12.9)$ \\
\hline Iorio et al. ${ }^{14)}$ & MA, MPTA, $\triangle \mathrm{PSA}$ & $1 / 14(7.1)$ & $12 / 14(86)$ & $1 / 14(7.1)$ & $8 / 13(38.5)$ & $3 / 13(23.0)$ & $2 / 13(15.4)$ \\
\hline Kim et al. ${ }^{15)}$ & MA, MA\%, PSA (1 yr) & $\mathrm{N} / \mathrm{M}$ & $\mathrm{N} / \mathrm{M}$ & $\mathrm{N} / \mathrm{M}$ & $\mathrm{N} / \mathrm{M}$ & $\mathrm{N} / \mathrm{M}$ & $\mathrm{N} / \mathrm{M}$ \\
\hline $\begin{array}{l}\text { Maurer and } \\
\text { Wassmer }^{16)}\end{array}$ & MA & $12 / 37(32.4)$ & $24 / 37(64.9)$ & $1 / 37(2.7)$ & $13 / 20(65.0)$ & $6 / 20(30.0)$ & $1 / 20(5.0)$ \\
\hline Reising et al. ${ }^{17)}$ & MA\% & $0(0)$ & $40 / 40(100)$ & $0(0)$ & $4 / 40(10.0)$ & $31 / 40(77.5)$ & $5 / 40(12.5)$ \\
\hline $\begin{array}{l}\text { Saragaglia and } \\
\text { Roberts }^{19)}\end{array}$ & MA & $\mathrm{N} / \mathrm{M}$ & $28 / 28(97)$ & $\mathrm{N} / \mathrm{M}$ & $\mathrm{N} / \mathrm{M}$ & $20 / 28(71)$ & $\mathrm{N} / \mathrm{M}$ \\
\hline Ribeiro et al. ${ }^{18)}$ & MA, PSA & $\mathrm{N} / \mathrm{M}$ & $\mathrm{N} / \mathrm{M}$ & $\mathrm{N} / \mathrm{M}$ & $\mathrm{N} / \mathrm{M}$ & $\mathrm{N} / \mathrm{M}$ & $\mathrm{N} / \mathrm{M}$ \\
\hline
\end{tabular}

FTA: femoro-tibial angle, MPTA: medial proximal tibial angle, PSA: posterior slope angle, TS: tibial slope, MA: mechanical axis, N/M: not mentioned. 


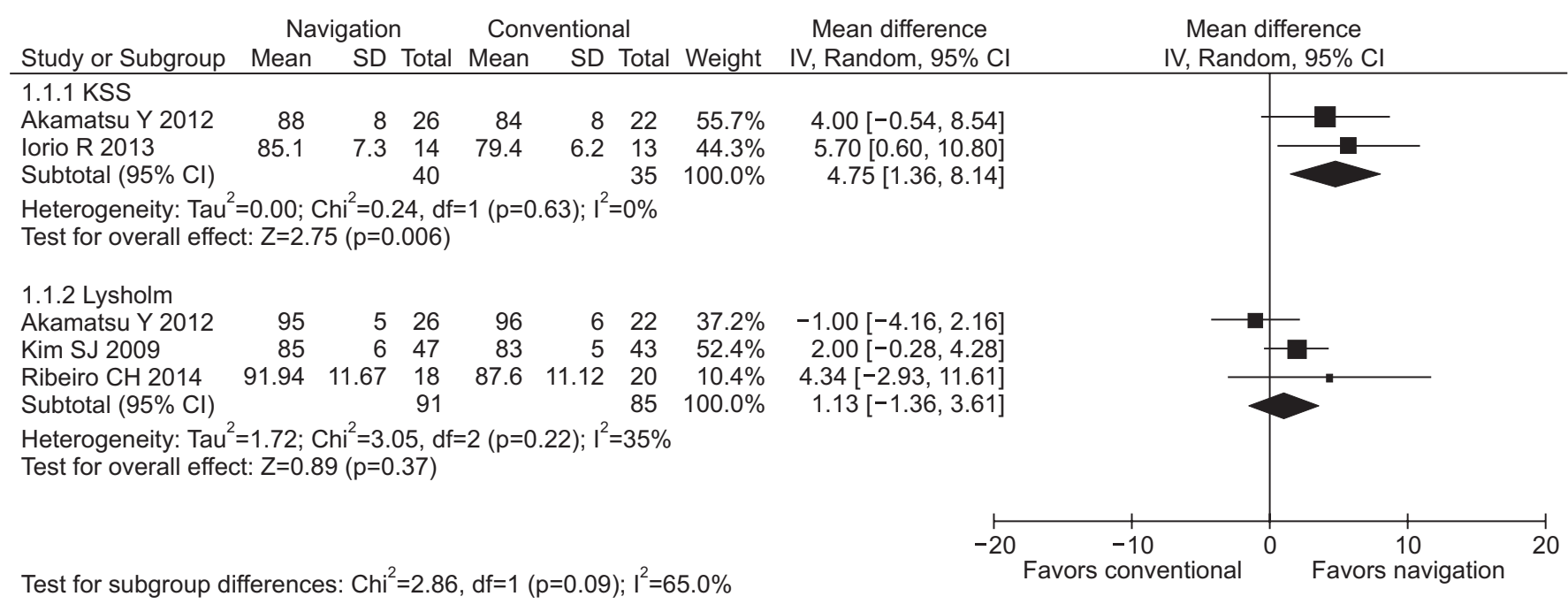

Fig. 2. Comparison of clinical outcomes between navigation-assisted high tibial osteotomy (HTO) and conventional HTO. Although the forest plot demonstrated a general trend in clinical outcomes (Knee Society score [KSS], Lysholm) favoring navigation-assisted HTO, there were not sufficient study results to determine statistical significance in the meta-analysis. SD: standard deviation, CI: confidence interval.

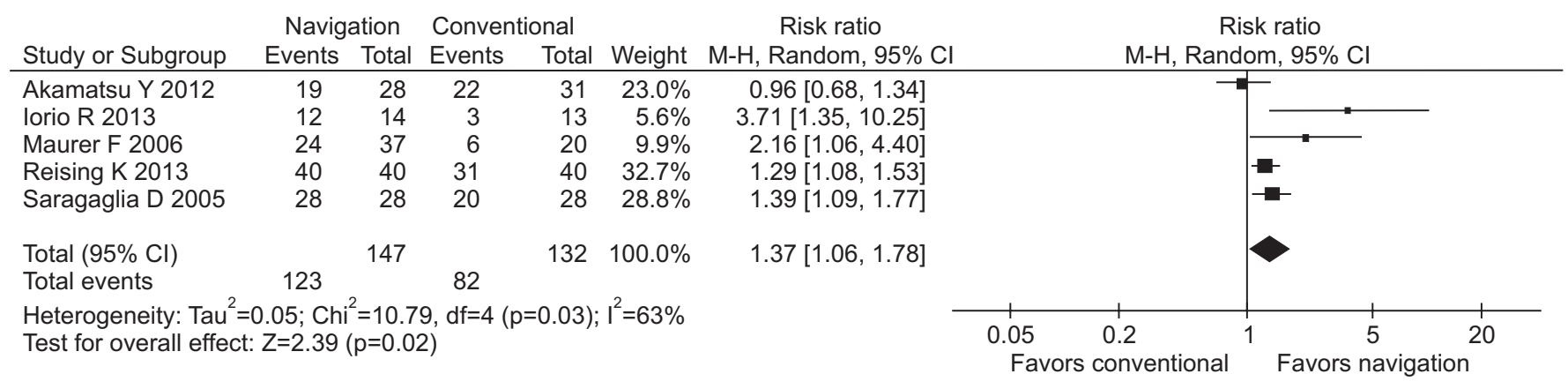

Fig. 3. Comparison of navigation-assisted high tibial osteotomy (HTO) and conventional HTO with respect to the risk ratio of outliers (mechanical axis of less than $0^{\circ}$ or more than $6^{\circ}$ ). CI: confidence interval.

ing satisfactory alignment. However, the meta-analysis showed no notable clinical benefit of computer-assisted HTO. Out of 7 recruited studies, 3 studies $^{16,17,19)}$ did not report preoperative and postoperative clinical outcome. The other 4 studies demonstrated heterogeneity in clinical scoring systems, rendering it impossible to obtain statistical significance in the meta-analysis. Therefore, clinical superiority of the navigation system for open wedge HTO could not be demonstrated. To our knowledge, this is the first meta-analysis comparing navigation-assisted HTO with conventional HTO.

The majority of previous reports on HTO define correction target as an intersection of the MA with the tibial plateau at $62 \%{ }^{22)}$. However, reports regarding the postoperative limb alignment variables have been different. The acceptable range was defined as $50 \%-70 \% \mathrm{MA} \%$ in some studies ${ }^{17,23,24)}$. An ideal range was suggested as $60 \%-70 \%$ MA $\%$ by Miniaci et al. ${ }^{25)}$. Dugdale et al. ${ }^{26)}$ proposed 50\%-75\% MA\% as the acceptable range. Some authors suggested acceptable range as FTA of $8^{\circ}-12^{\circ}$ valgus ${ }^{27,28)}$. Five out of 7 studies reported postoperative radiological outliers. Those studies presented the "acceptable" range as within $0^{\circ}-6^{\circ}$ of MA (Table 4). In the 5 studies (279 knees), the MA was within the acceptable range in $83.7 \%$ (range, $65 \%$ to $100 \%$ ) of the computerassisted navigation HTO group, which was significantly higher than $62.1 \%$ (range, $23 \%$ to $78 \%$ ) of the conventional HTO group $\left(\mathrm{RR}=1.37, \mathrm{p}<0.01,95 \% \mathrm{CI}\right.$ [1.06-1.78], $\left.\mathrm{I}^{2}=63 \%\right)$ (Fig. 3). Regarding the MA outliers, computer-assisted navigation significantly reduced the incidence of outliers compared to the conventional method.

All 7 included studies reported postoperative radiological parameters, 2 studies ${ }^{15,18)}$, however, did not report the range of outliers. They only reported the absolute values of limb alignment. Kim et al. ${ }^{15)}$ reported a postoperative mean MA of $3.9^{\circ}$ (standard 


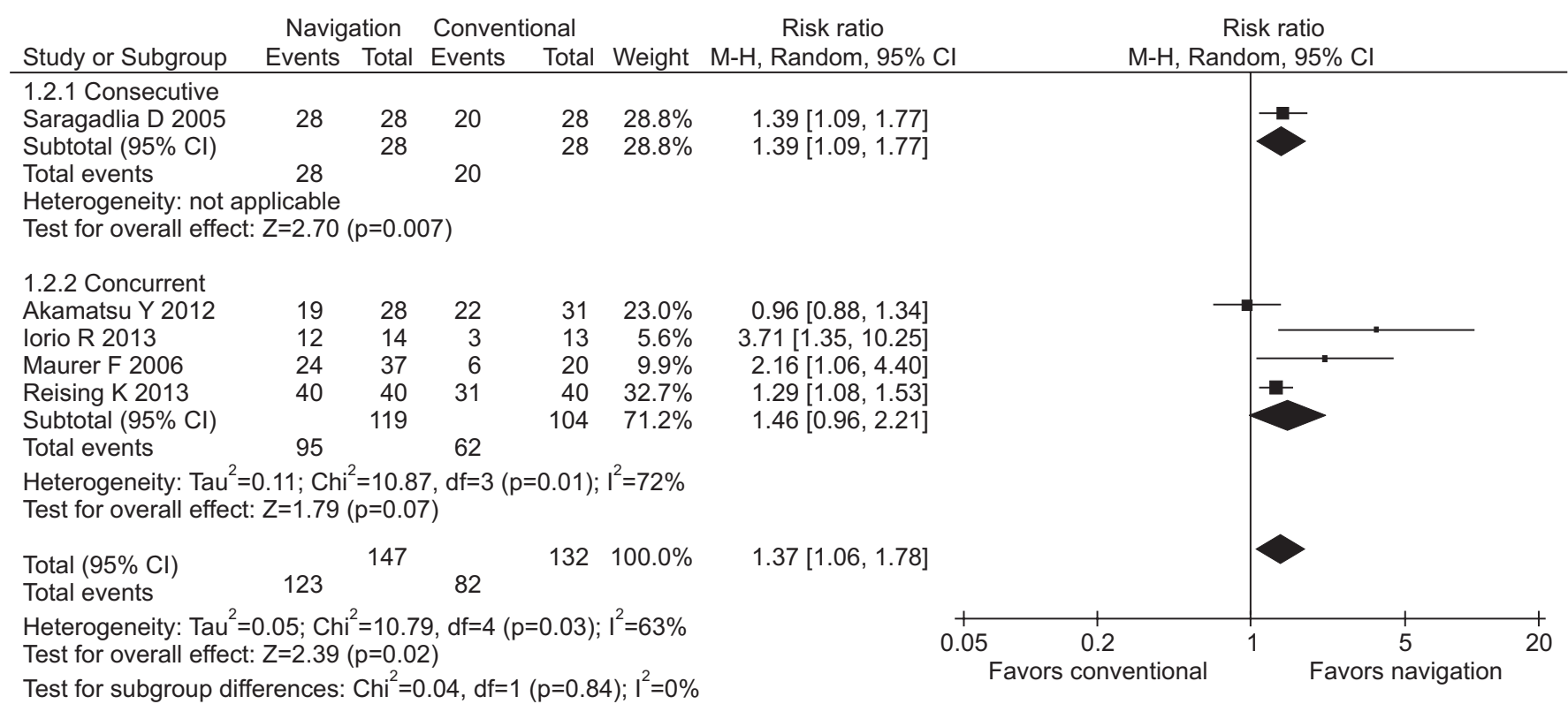

Fig. 4. Subgroup (consecutive vs. concurrent patient series) analysis comparing navigation-assisted high tibial osteotomy (HTO) and conventional HTO with respect to the risk ratio of outliers (mechanical axis of less than $0^{\circ}$ or more than $6^{\circ}$ ). CI: confidence interval.

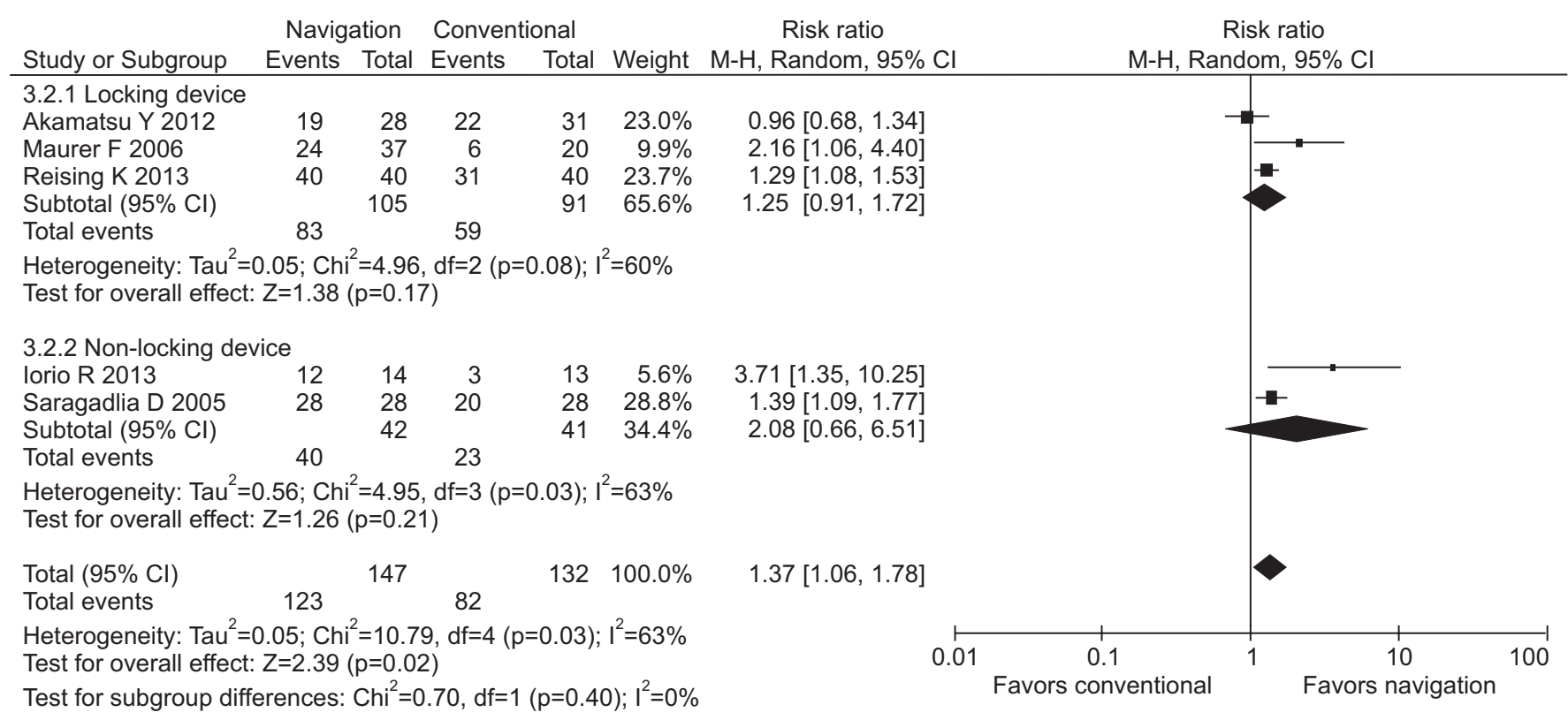

Fig. 5. Subgroup (fixation with a locking device vs. a non-locking device) analysis comparing navigation-assisted high tibial osteotomy (HTO) and conventional HTO with respect to the risk ratio of outliers (mechanical axis of less than $0^{\circ}$ or more than $6^{\circ}$ ). CI: confidence interval.

deviation $[\mathrm{SD}], 1^{\circ}$ ) for the navigation HTO group, and $2.7^{\circ}$ (SD, $2.2^{\circ}$ ) for the conventional HTO group. They also reported a mean MA\% of $62.3 \%$ (SD, 2.9\%) for the navigation HTO group and $58.7 \%$ (SD, 6.6\%) for the conventional group. The SD values for both MA and MA\% increased statistically significantly in the conventional HTO group. Ribeiro et al. ${ }^{18)}$ reported a postoperative mean MA of $3.06^{\circ}\left(\mathrm{SD}, 1.76^{\circ}\right)$ for the navigation HTO group, and $3.35^{\circ}\left(\mathrm{SD}, 3.27^{\circ}\right)$ for the conventional HTO group. In their study, the SD values also increased in the conventional HTO group compared to the navigation HTO group. Reports of lower $\mathrm{SD}$ values may refer to lower occurrences of outliers which are consistent with the findings of this meta-analysis.

The type of open wedge HTO study design being consecutive or concurrent $\left(\mathrm{I}^{2}=0 \%\right)$, the use of bone graft material at the oste- 
otomy gap, and the use of locking device for fixation $\left(\mathrm{I}^{2}=0 \%\right)$ may all affect the outcome of HTO regardless of the use of computerassisted navigation system. However, these variable factors did not show any difference in the subgroup analysis (Figs. 4 and 5). Further studies are necessary for analysis regarding these issues.

Several limitations of this study should be noted. First, as other meta-analysis studies, results of this study may have been affected by the type and number of variables incorporated into the primary studies. Second, all included studies for this meta-analysis were retrospective comparative studies. Thus, inherent heterogeneity among studies should be taken into consideration $\left(\mathrm{I}^{2}=63 \%\right.$, Fig. 3 ), and further well designed randomized control trials should be performed to confirm our conclusions. Third, the sample sizes of the studies were small; most of the study had less than 50 patients. Fourth, since all the studies used radiographic parameters, such as MA, MA\%, MPTA, and FTA, for postoperative assessment, there is a potential for inherent measurement errors. Lastly, a meta-analysis could not be performed on clinical outcomes due to the heterogenic reports of clinical scoring systems as well as the lack of reports on clinical assessments.

\section{Conclusions}

The present meta-analysis indicates that the use of navigation in patients undergoing open wedge HTO improves the precision of MA by decreasing the incidence of outliers. However, the clinical benefit of navigation-assisted HTO is not conclusive. Additionally, none of the subgroup analyses according to the study period and the use of a locking fixation device demonstrated significant difference in the RR of MA outliers.

\section{Conflict of Interest}

No potential conflict of interest relevant to this article was reported.

\section{References}

1. Coventry MB. Osteotomy of the upper portion of the tibia for degenerative arthritis of the knee: a preliminary report. J Bone Joint Surg Am. 1965;47:984-90.

2. Brouwer RW, Huizinga MR, Duivenvoorden T, van Raaij TM, Verhagen AP, Bierma-Zeinstra SM, Verhaar JA. Osteotomy for treating knee osteoarthritis. Cochrane Database Syst Rev. 2014;12:CD004019.

3. Rampersaud YR, Pik JH, Salonen D, Farooq S. Clinical ac- curacy of fluoroscopic computer-assisted pedicle screw fixation: a CT analysis. Spine (Phila Pa 1976). 2005;30:E183-90.

4. Stockle U, Krettek C, Pohlemann T, Messmer P. Clinical applications: pelvis. Injury. 2004;35 Suppl 1:S-A46-56.

5. Amiot LP, Poulin F. Computed tomography-based navigation for hip, knee, and spine surgery. Clin Orthop Relat Res. 2004;(421):77-86.

6. Wang G, Zheng G, Keppler P, Gebhard F, Staubli A, Mueller U, Schmucki D, Fluetsch S, Nolte LP. Implementation, accuracy evaluation, and preliminary clinical trial of a CT-free navigation system for high tibial opening wedge osteotomy. Comput Aided Surg. 2005;10:73-85.

7. Cheng T, Zhao S, Peng X, Zhang X. Does computer-assisted surgery improve postoperative leg alignment and implant positioning following total knee arthroplasty? A metaanalysis of randomized controlled trials? Knee Surg Sports Traumatol Arthrosc. 2012;20:1307-22.

8. Fu D, Li G, Chen K, Zhao Y, Hua Y, Cai Z. Comparison of high tibial osteotomy and unicompartmental knee arthroplasty in the treatment of unicompartmental osteoarthritis: a meta-analysis. J Arthroplasty. 2013;28:759-65.

9. Fu Y, Wang M, Liu Y, Fu Q. Alignment outcomes in navigated total knee arthroplasty: a meta-analysis. Knee Surg Sports Traumatol Arthrosc. 2012;20:1075-82.

10. Weber P, Crispin A, Schmidutz F, Utzschneider S, Pietschmann MF, Jansson V, Muller PE. Improved accuracy in computer-assisted unicondylar knee arthroplasty: a metaanalysis. Knee Surg Sports Traumatol Arthrosc. 2013;21: 2453-61.

11. Bae DK, Song SJ, Yoon KH. Closed-wedge high tibial osteotomy using computer-assisted surgery compared to the conventional technique. J Bone Joint Surg Br. 2009;91:116471.

12. Higgins JP, Thompson SG, Deeks JJ, Altman DG. Measuring inconsistency in meta-analyses. BMJ. 2003;327:557-60.

13. Akamatsu Y, Mitsugi N, Mochida Y, Taki N, Kobayashi H, Takeuchi R, Saito T. Navigated opening wedge high tibial osteotomy improves intraoperative correction angle compared with conventional method. Knee Surg Sports Traumatol Arthrosc. 2012;20:586-93.

14. Iorio R, Pagnottelli M, Vadala A, Giannetti S, Di Sette P, Papandrea P, Conteduca F, Ferretti A. Open-wedge high tibial osteotomy: comparison between manual and computerassisted techniques. Knee Surg Sports Traumatol Arthrosc. 2013;21:113-9.

15. Kim SJ, Koh YG, Chun YM, Kim YC, Park YS, Sung CH. 
Medial opening wedge high-tibial osteotomy using a kinematic navigation system versus a conventional method: a 1-year retrospective, comparative study. Knee Surg Sports Traumatol Arthrosc. 2009;17:128-34.

16. Maurer F, Wassmer G. High tibial osteotomy: does navigation improve results? Orthopedics. 2006;29(10 Suppl):S130-2.

17. Reising K, Strohm PC, Hauschild O, Schmal H, Khattab M, Sudkamp NP, Niemeyer P. Computer-assisted navigation for the intraoperative assessment of lower limb alignment in high tibial osteotomy can avoid outliers compared with the conventional technique. Knee Surg Sports Traumatol Arthrosc. 2013;21:181-8.

18. Ribeiro CH, Severino NR, Moraes de Barros Fucs PM. Opening wedge high tibial osteotomy: navigation system compared to the conventional technique in a controlled clinical study. Int Orthop. 2014;38:1627-31.

19. Saragaglia D, Roberts J. Navigated osteotomies around the knee in 170 patients with osteoarthritis secondary to genu varum. Orthopedics. 2005;28(10 Suppl):s1269-74.

20. Wells GA, Shea B, O'Connell D, Peterson J, Welch V, Losos M, Tugwell P. The Newcastle-Ottawa Scale (NOS) for assessing the quality of nonrandomised studies in meta-analyses [Internet]. Ottawa, ON: Ottawa Hospital Research Institute; 2011 [cited 2014 Oct 15]. Available from: http://www.ohri. ca/programs/clinical_epidemiology/oxford.asp.

21. Hankemeier S, Hufner T, Wang G, Kendoff D, Zeichen J, Zheng G, Krettek C. Navigated open-wedge high tibial osteotomy: advantages and disadvantages compared to the conventional technique in a cadaver study. Knee Surg Sports
Traumatol Arthrosc. 2006;14:917-21.

22. Fujisawa Y, Masuhara K, Shiomi S. The effect of high tibial osteotomy on osteoarthritis of the knee: an arthroscopic study of 54 knee joints. Orthop Clin North Am. 1979;10:585608.

23. Niemeyer P, Koestler W, Kaehny C, Kreuz PC, Brooks CJ, Strohm PC, Helwig P, Suedkamp NP. Two-year results of open-wedge high tibial osteotomy with fixation by medial plate fixator for medial compartment arthritis with varus malalignment of the knee. Arthroscopy. 2008;24:796-804.

24. Niemeyer P, Schmal H, Hauschild O, von Heyden J, Südkamp NP, Kostler W. Open-wedge osteotomy using an internal plate fixator in patients with medial-compartment gonarthritis and varus malalignment: 3 -year results with regard to preoperative arthroscopic and radiographic findings. Arthroscopy. 2010;26:1607-16.

25. Miniaci A, Ballmer FT, Ballmer PM, Jakob RP. Proximal tibial osteotomy: a new fixation device. Clin Orthop Relat Res. 1989;(246):250-9.

26. Dugdale TW, Noyes FR, Styer D. Preoperative planning for high tibial osteotomy. The effect of lateral tibiofemoral separation and tibiofemoral length. Clin Orthop Relat Res. 1992; (274):248-64.

27. Coventry MB. Osteotomy about the knee for degenerative and rheumatoid arthritis. J Bone Joint Surg Am. 1973;55:2348.

28. Insall JN, Joseph DM, Msika C. High tibial osteotomy for varus gonarthrosis: a long-term follow-up study. J Bone Joint Surg Am. 1984;66:1040-8. 